\section{Dynamic Capabilities: A Measurement Proposal and its Relationship with Performance}

\author{
Ivan Lapuente Garrido ${ }^{1}$ \\ igarrido@unisinos.br | @0000-0003-3741-7961 \\ Caroline Kretschmer ${ }^{1}$ \\ ckretschmer@edu.unisinos.br| (D)0000-0002-3318-0947 \\ Silvio Luis de Vasconcellos ${ }^{2}$ \\ slvasconcellos@furb.br| (DD0000-0002-9986-679X \\ Cláudio Reis Gonçalo ${ }^{3}$ \\ claudioreisgoncalo@gmail.com | (DD0000-0002-1175-1104
}

\begin{abstract}
Despite the relevance and growth of research into Dynamic Capabilities, certain gaps and criticisms remain. These issues are primarily related to the measurements of Dynanic Capabilities and its impacts on performance. There is a lack of empirical research that is attempting to investigate the existence, development, and orchestration of Dynamic Capabilities to support superior performance. This paper proposes and validates a scale for the measurement of Dynamic Capabilities based on Teece's conceptual dimensions (sense, seizing and reconfiguring) through a survey presented in a highly dynamic industry and market, and by investigating the impact on performance. The results, besides validating the scale, showed Teece's three conceptual dimensions exhibited different behavior in relation to each dimension of performance. Sense and Reconfiguration demonstrated a negative relationship with organizational performance while Seize is positively associated with performance. This may help explain some of the fuzzy results of previous studies that used proxies to measure Dynamic Capabilities.
\end{abstract}

\section{KEYWORDS}

Dynamic Capabilities, Information Technology, Performance, Scale
${ }^{1}$ Universidade do Vale do Rio dos Sinos, Porto Alegre, RS, Brasil

${ }^{2}$ Universidade Regional de Blumenau, Blumenau, SC, Brasil

${ }^{3}$ Universidade do Vale do Itajaí, Itajaí, SC, Brasil

Received: 12/20/2018

Revised: 04/11/2019.

Accepted: 05/23/2019.

Published Online: 12/23/2019.

DOI: http://dx.doi.org/10.15728/bbr.2020.17.1.3 


\section{INTRODUCTION}

The Dynamic Capabilities (DCs) perspective is a subject of great interest in the area of strategic management studies (Vogel \& Güttel, 2013). Since it was developed during the 1990s, a great deal of research has been conducted to conceptualize and delineate its underlying elements and assumptions (Ambrosini \& Bowman, 2009). However, there are a number of distinct views on how DCs should be conceptualized and applied in the area of strategy studies that are disconnected from each other (Eisenhardt \& Martin, 2000; Vogel \& Güttel, 2013), causing confusion and possibly creating obstacles to development in this area (Barreto, 2010). This paper proposes a method of measurement of DCs and also discusses the role they play in organizational performance (OP).

In the permanent and rapid changes that characterize the competitive business environment, customers' needs, technology and the actions of competitors represent new opportunities for firms, but they are also risks that threaten their survival and growth (Teece, 2007). Responding to this background, the DCs approach offers a different perspective from which to understand the sources of competitive advantage, since it proposes a framework for understanding the way that organizations construct and maintain a competitive advantage in complex and constantly changing environments (Teece, Pisano, \& Shuen, 1997). From the DCs perspective, a strategy for obtaining a competitive advantage starts with the adoption of the appropriate business models and technologies that enable combination and orchestration of assets that are difficult to replicate (Teece, 2007).

Despite the relevance of the subject, empirical studies investigating DCs remain no more than incipient (Laaksonen \& Peltoniemi, 2018). There is a lack of research attempting to confirm their existence, to identify the processes by which they are developed, to determine which contingency factors affect them, and what their effects on an organization might be, such as, for example, what impact they have on performance (Helfat \& Peteraf, 2009; Shamsie, Martin, \& Miller, 2009). One factor that may be contributing to these gaps in the literature, and the criticisms the approach has attracted, is the failure to reach a consensus on methods for measuring DCs. Applied research has employed a range of proxies to measure them, possibly without effectively reflecting the concept (Pavlou \& Sawy, 2011). Supporting such spread of approaches, Laaksonen \& Peltoniemi (2018) found 232 different operationalizations of DCs in a review of empirical studies on DCs. Eriksson (2014) points out the need for the development of DCs measurement.

In the direction of contributing to filling these gaps and stemming criticism of the concept, this study is designed to fulfill two basic objectives. The first objective is to propose a scale for measurement of DCs that encompasses various different dimensions of the concept (Sense, Seize and Managing Threats and Reconfiguration) as proposed by Teece (2007). The second objective is to assess the role played by DCs and their dimensions within the different dimensions of organizational performance. DCs is a multidimensional concept and its different dimensions can have different influences on performance.

In order to fulfill these twin objectives, we conducted a study in two distinct phases. In the first phase, which was exploratory and qualitative, we proposed a scale based on the dimensions of DCs defined by Teece (2007): "Sense new opportunities and threats"(Sense); "Seize new opportunities" (Seize); and "Managing threats and reconfiguration"(MTR). In addition to these, we integrated additional indicators from other studies (Eisenhardt \& Martin, 2000; Zahra \& George, 2002; Zollo \& Winter, 2002) dealing with the same subject.

The second stage was descriptive and quantitative, consisting of testing the scale by conducting a survey of managers working in the Brazilian Information Technology (IT) industry. This industry and market are suited to this line of research because both the industry and the market (country) 
are highly dynamic, with a rapid rate and high volume of change andspeed of introduction of innovations, as well as being knowledge-intense and highly competitive (Teece et al., 1997).

The results provide evidence showing that the proposed multidimensional scale has an adequate fit and that DCs have a positive influence on OP while revealing the different behavior of each dimension (Sense, Seize, and MTR) in relation to DCs and to the performance itself.

\section{THEORETICAL FRAMEWORK}

The first formal definition of DCs was presented in a seminal article by Teece et al. (1997), which opened the way to a fertile and diverse field of research within the area of strategic management studies (Di Stefano, Peteraf, \& Verona, 2010). Teece et al. (1997) conceptualized DCs as "the firm's ability to integrate, build and reconfigure internal and external competences to address rapidly changing environments" (p. 516). This concept is concerned with proactive methods of finding different and innovative paths to achieving competitive advantage (Teece et al., 1997).

DCs are capabilities which are capable of purposefully creating, amplifying, and modifying their resource bases (Teece, 2019; Teece et al., 1997). The scope of DCs permeates a firm's ability to not only mold the ecosystem in which it does business, but also to develop new products, processes, and business models, while enabling the organization to adapt to technological opportunities and changes in customers' demands (Teece, 2014; Teece, 2007). However, the construct of DCs is permeated by a variety of interpretations and conceptualizations and its concepts and underlying elements change from researcher to research (Di Stefano et al., 2010).

Notwithstanding, the different definitions of DCs do converge in terms of identifying them as organizational processes that enable firms to change their resource bases. These capabilities are constructed, they are dependent on the organization's path, and they are incorporated into the firm (Helfat et al., 2007). These processes are integrated and rooted in the firm, they are not easily codifiable or transferable, but they enable firms to implement resources in conjunction, combining explicit activities and tacit elements (such as know-how and leadership), and are developed over time as a result of complex interactions between a firm's resources (Wang \& Ahmed, 2007). According to Teece et al. (1997), the competitive advantage depends on the firm's managerial processes (the way things are done), their asset position (current assets, intellectual property, complementary assets, customer base, and external relations), and their paths (possible strategic alternatives, returns and path dependence).

DCs are made up of a combination of company history, values, and routines, as well as the skills of top management, enabling a firm to invest in new products, processes, and business models at the appropriate time and with reference to assessments of the technological and business environment (Teece, 2014).

Given the scope and complexity of the subject, different studies have focused on specific elements of DCs. Zollo and Winter (2002) consider that one prerequisite for DCs is stability in the organizational activities that develop improvements and modifications to operational routines to improve their effectiveness. Learning mechanisms and the firm's ability to combine and recombine assets to produce improvements are characteristic of DCs. Zahra and George (2002) link DCs with the firm's absorptive capacity, which enables it to generate and introduce the knowledge needed to create other organizational capabilities, via organizational routines and strategic processes. In the view of Eisenhardt and Martin (2000) DCs are organizational and strategic routines that make possible new resource configurations in changing markets. They see DCs as a firm's best practices that it has adopted in advance of its competitors. They list routines for knowledge transference and recombination, routines for product development and quality 
control, and research and development (R\&D) teams as important elements for supporting DCs. Finally, Teece (2007) broke down DCs into three capabilities or dimensions: (1) Sense and shape opportunities and threats (Sense) (2) Seize opportunities (Seize), and (3) Managing threats and reconfiguration (MTR). He also proposed a series of indicators, or microfoundations originating in the literature on strategy, innovation and organization (Teece, 2007).

The figure below (Chart 1) illustrates the results of the integration of these different perspectives. It is based on the foundation proposed by Teece (2007) since this is the most comprehensive and instructive proposal, and then elements from other studies were integrated into this proposal. The resulting integration is the basis of the scale used in this study.

Chart 1

Dimensions of DCs and their Microfoundations

Capabilities and Microfoundations

Sense: search for and explore opportunities in technologies and markets

- Constant investment in R\&D; identify customer needs; collect information from different sources and filter it; monitor the activities of competitors, customers, and suppliers; monitor the structural evolution of the business;

Teece (2007) monitor internal and external technological development.

- Accumulate tacit knowledge through experience and acts of creativity.

Zollo and Winter, (2002)

- Acquire knowledge and develop mechanisms to receive knowledge transfers.

Zahra and George (2002)

- Develop routines for knowledge creation in which management and workers

Eisenhardt and Martin build "new thinking" within the firm.

(2000)

Seize: transformation of these opportunities into new products, services, and processes

- Develop new products, processes, and services; focus on management and on functional activities; invest in technology and design to reach a target market; create, adapt, improve and, if necessary, substitute business models; acquire Teece (2007) technologies externally and develop them internally; perfect absorptive capacity through learning activities and accumulation of skills.

- Articulate knowledge

Zollo and Winter, (2002)

- Routines for assimilation and internalization of knowledge; taking strategic decisions.

Zahra and George (2002)

MTR: reconfiguration and recombination of assets and organizational structure to ensure the evolution of the firm

- Define partnerships in the value chain; decentralize activities and decisions; flexibility; orchestrate assets, align them, realign them and redistribute them; capability to integrate external knowledge and assets; capability to share

Teece (2007) knowledge; monitor, and protect technology transfer and intellectual property.

- Develop processes for knowledge codification to disseminate it and to generate new proposals for altering the firm's routines.

Zollo and Winter, (2002)

- Exploit the new knowledge created.

Zahra and George (2002)

- Reconnect networks of collaborations of the firm to generate new combinations of resources; abandon resource combinations that no longer provide a competitive advantage.

Eisenhardt and Martin

(2000)

Source: Author's own elaboration. 


\subsection{DifFERENT MEASUREMENTS}

One of the most obvious sources of complexity in empirical articles on DCs is the conceptual breadth adopted, and the methods of measuring them. Some studies assess DCs by evaluating the development of new products and markets (Schilke, 2014; Shamsie et al., 2009), others seek evidence of innovation and technology or even of R\&D investment (Danneels, 2012; Efrat, Hughes, Nemkova, Souchon, \& Sy-Changco, 2018); marketing capabilities (Pedron, Picoto, Colaco, \& Araújo, 2014); alliance and partnership formation and acquisitions have also been used (Castro \& Roldán, 2015; Schilke, 2014); as have learning capability (Lin \& Wu, 2014); and strategic flexibility (Efrat et al., 2018), among other indicators.

However, when compared to the parameter provided by Teece's proposal (2007), it is found that the concepts and methods of measurement listed are somehow incomplete. In some cases, they encompass part of the concept of DCs but do not include all of its dimensions. In our analysis, only in Wilden, Gudergan, Nielsen, \& Lings (2013), Takahashi, Bulgacov, Semprebon e Giacomini (2017), and Wilden e Gudergan (2017), the three dimensions proposed by Teece (2007) are present, despite the indicators in each construct did not integrate Teece's concept completely. For example, the authors did not ask about the capacity to build a business model in the Seize construct or about the practices to identify new technologies in the Sense construct.

\subsection{DCs AND OP}

There is some criticism about the relationship between DCs and superior performance once a positive relationship was not found in all empirical studies analyzed (Pezeshkan, Fainshmidt, Nair, Lance Frazier, \& Markowski, 2016). A possibility is that there is not a direct relationship between DC and performance. In this sense, to Teece (2014) DCs and business strategies codetermine performance. Also to Ambrosini \& Bowman (2009) the firm's resources, the operational routines, and competencies, can affect the relationship between CDs and performance. In line with this, Laaksonen \& Peltoniemi (2018) propose that DCs are dependent on the companies' ordinary capabilities, modified by DCs and by the evolutionary fitness of these capabilities.

Despite such controversial positions, the literature suggests a positive relationship between DCs and performance. DCs make it possible for organizations to identify and implement the best way to construct and maintain their competitive advantage in complex and constantly changing environments (Kay, Leih, \& Teece, 2018; Teece et al., 1997). The DCs perspective is closely related to OP since possession and orchestration of these capabilities alter a firm's base of competencies, operational routines, and resources, which can change its market position and, consequently, its performance (Zott, 2003).

It is by arranging their resources that the organizations that possess them develop capabilities and arrive at systematic models for their organizational activities, which allow them to generate and adapt their routines to achieve greater efficiency (Zollo \& Winter, 2002). As a response to OP, DCs enable improved response capability for dealing with environmental changes, offering opportunities to increase revenue and adjust operations to reduce costs (Drnevich \& Kriauciunas, 2011; Kay, Leih, \& Teece, 2018).

\subsection{The MEASUREMENT MODEL}

Figure 1 illustrates the model on which the proposal described in this paper is based. It is founded on the understanding that DCs reveal their existence in the form of the capacity to generate better $\mathrm{OP}$ in constantly changing environments. 


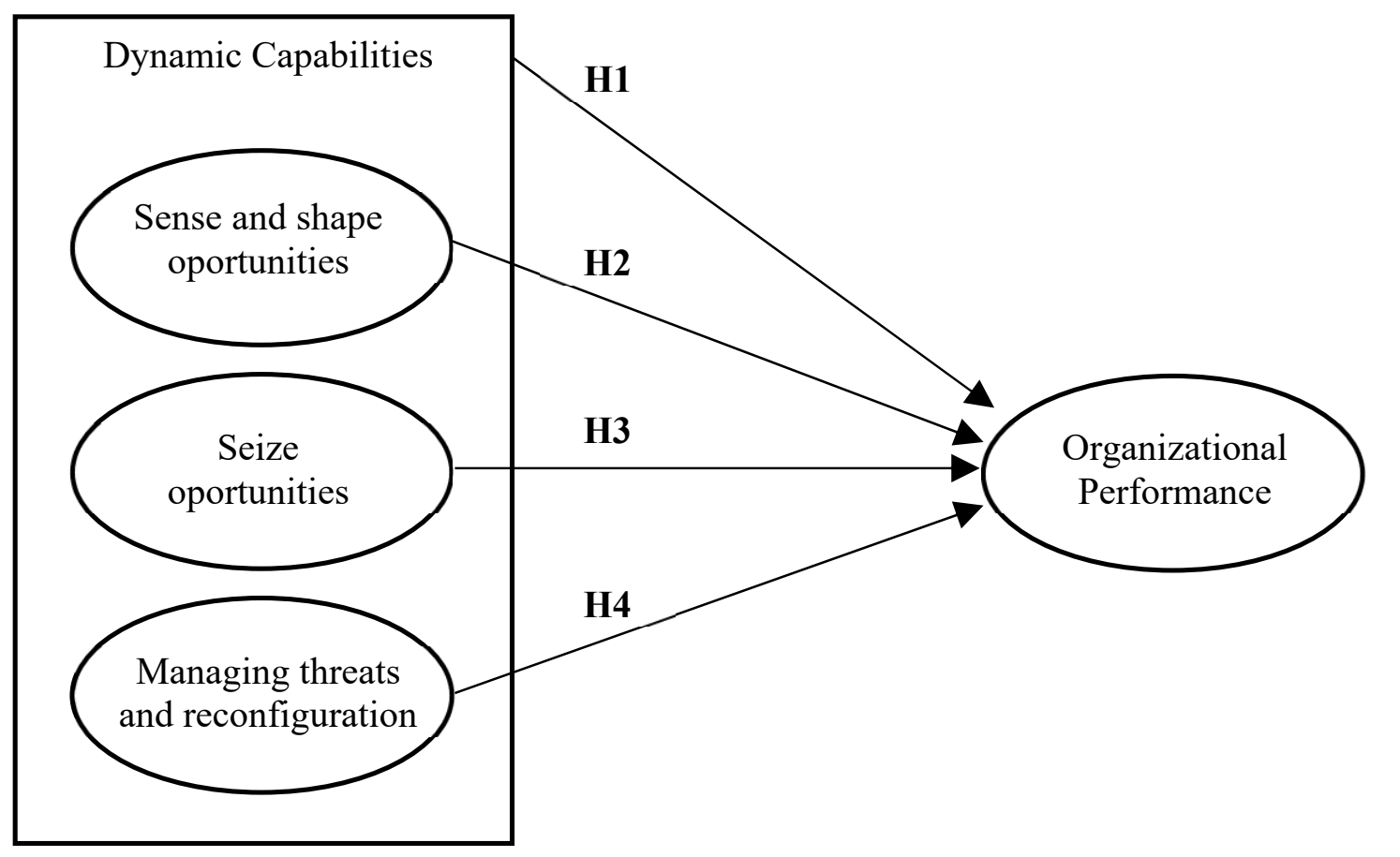

Figure 1. Research framework.

Source: Author's own elaboration.

The underlying foundation of the model is the relationship between DCs and OP. Many studies have proposed and confirmed this relationship, such as, for example, Schilke (2014), Teece (2007), and Wang and Ahmed (2007), among others. However, the model presented in this paper is different from previous empirical studies and is a positive evolution in relation to them because of two central elements. The first of these elements is the scale designed specifically to measure DCs, created using the basic framework defined by Teece (2007) and supplemented with aspects from other studies, but without relying on proxies to capture DCs, as is usually proposed. This offers a more comprehensive and complete measurement and could contribute a basis for conducting studies that can be compared with each other. The second of these elements is that the proposal acknowledges the full complexity of the concept of DCs and breaks down measurement of it into its distinct dimensions of "Sense", "Seize", and "MTR" (Teece, 2007). This element is important, because each of these capabilities has different concepts and functions and, and, even though they are all components of DCs, they may have different relationships with OP or have different roles to play in achieving it. Investigating their behavior, both in relation to DCs and in relation to organizational performance, should contribute to advancing research into the subject.

Working from these arguments, and within the research framework shown above, we raise the following hypotheses:

- H1: There is a positive and significant relationship between DCs and OP;

- H2: There is a positive and significant relationship between Sense and OP;

- H3: There is a positive and significant relationship between Seize and OP;

- H4: There is a positive and significant relationship between MTR and OP. 
BBR

17

52

\section{METHODS}

We conducted this study in two phases. The first phase was qualitative and exploratory and consisted of the construction of the proposed scale to measure DCs and a model to guide the empirical component of the study. The second phase was descriptive and quantitative and consisted of testing the proposed scale and model using cross-sectional data from the Brazilian IT industry.

\subsection{EMPIRICAL CONTEXT}

We chose the Brazilian IT industry (software, hardware and telecommunications companies) because it is a turbulent environment, both in terms of the industry and in terms of the market (the political and economic crisis in Brazil (2015-2017) represented a sui generis opportunity to evaluate how firms immersed in a turbulent scenario developed DCs). This combination is a setting in which there is a great deal of change, a high rate of introduction of innovations, high knowledge intensity, and a high degree of competitiveness, making it very appropriate for investigating the role of DCs.

\subsection{Qualitative Phase}

Starting from the Teece's model (2007) and drawing on the other articles that made up the synthesis of theoretical references illustrated in Figure 1 (Eisenhardt \& Martin, 2000; Zahra \& George, 2002; Zollo \& Winter, 2002) we constructed a scale that comprised indicators for each of the dimensions, Sense, Seize, and MTR. This scale was discussed with seven entrepreneurs from the IT industry in October and November 2015. These entrepreneurs were chosen on the basis of recommendations made by Assespro (the Brazilian association of IT companies) and the most important criteria were their breadth of experience in the IT industry and their status as top-level managers in their respective firms. This phaseing was important to fit the wording of the indicators to a managerial language. We asked each respondent to answer the questionnaire and after that, we discussed each question.

\subsection{Quantitative Phase}

We collected the data from between December 2015 to March 2016 by means of a survey. The firms surveyed were selected from lists of the members of industry associations. The questionnaire was administered by telephone. The respondents were executives with responsibility for firm strategy. We conducted a pre-test with 34 firms to test the quality of the questionnaire. This resulted in a small number of changes to arrive at the final questionnaire. The most significant change was to set revenue bands for classifying firms by size that were more appropriate to the industry. The questionnaire was administered in Portuguese. A version in English is shown later in Table 6.

The questionnaire was administered to representatives from a sample of 99 firms. Just one firm was eliminated from the final sample because the questionnaire sent to them was returned a high number of unanswered questions. The final result was a sample of 98 firms for analysis. The characteristics of the firms that took part reflect the immense diversity of the Brazilian IT industry; $78 \%$ of them are software developers, $16 \%$ produce hardware and $5 \%$ are telecommunications firms. The mean number of employees per firm was 243 , but one firm has 10,000 employees, while the smallest only has one. The great majority of these firms (80\%) have revenues ofless than 10 million reais per year (about 3 million American dollars). 


\subsubsection{Independent Variables (IVs)}

The IVs are the three dimensions of DCs proposed by Teece (2007): Sense (SE), Seize (SZ) and Managing Threats and Reconfiguration (MTR). For each dimension, there are a series of statements and the respondent is requested to indicate the extent to which they agree with each one on a 5-point scale.

\subsubsection{Dependent Variable (DV)}

Ultimately, the DV is organizational performance, but we adopted several different dimensions of performance - financial performance (FP), strategic performance (SP), satisfaction with performance $(\mathrm{SaP})$, and innovation (IN).

The measures for FP, SP, and SaP were based on the EXPERF scale created by Zou, Taylor, and Osland (1998), in which each construct is comprised of three indicators and the focus is on the previous three years. Additionally, using an observable variable, the last DV is the respondent's perception of the firm's degree of innovation in relation to its competitors. For all of these indicators, responses are given on a 5-point scale of agreement.

In this study, we have employed subjective data, capturing the respondents' perceptions of each indicator assessed. We chose this method because we are studying a complex and heterogeneous industry with a high degree of informality and one in an emerging market where data collection is difficult, particularly so with respect to secondary data.

\subsubsection{Control Variables (CV)}

We chose firm experience (age of firm - AG) and size (number of employees - EM and revenue $-\mathrm{RV}$ ) as control variables. More experience implies more learning and commitment to the market and larger firm size is related to greater access to resources and potential to develop capabilities (Musteen, Francis, \& Datta, 2010).

\subsection{VALIDATION OF MEASURES AND ANALYTICAL PROCEDURES}

We assessed each construct separately using Confirmatory Factor Analysis (CFA), calculating composite reliability (CR), variance extracted (VE), Cronbach's alpha (CA), and factor loadings (FL) for each indicator against the construct. We also tested the discriminant validity of the constructs. Finally, we used the AMOS 16 to proceed with the Structural Equation Modeling (SEM) to test the DCs model's fit. We used the linear regression analysis from IBM SPSS statistics 20 to test the relationship between the IVs and the DV. We decided not to use SEM because of the sample size (Kline, 1998).

\section{RESULTS AND DISCUSSION}

\subsection{The Dynamic Capabilities Scale}

Because of the exploratory nature of this phase, the first version of the proposed scale was very long, comprising more than 50 indicators since the intention was to capture the essence of each dimension of DCs (Sense, Seize and MTR) and the initial expectation was that several of them might not adhere to the construct. First, each construct was evaluated separately using the norms for CFA, and, finally, the model's fit was evaluated using SEM. 
BBR

17

54

From the quantitative point of view, the dimension SE initially comprised 11 indicators and after confirmatory factor analysis the final construct had 5; SZ started with 19 indicators and ended with 8 and, finally, MTR originally had 12, while the final version comprised 8 indicators. Table 1 lists data for the reliability of the constructs.

Table 1

Reliability of DCs Dimensions

\begin{tabular}{lccccc}
\hline & SE & \multicolumn{2}{c}{ SZ } & \multicolumn{2}{c}{ MTR } \\
\hline Indicators & FL & Indicators & FL & Indicators & FL \\
SE3 & 0.924 & SZ15 & 0.606 & MTR34 & 0.674 \\
SE4 & 0.689 & SZ16 & 0.840 & MTR35 & 0.639 \\
SE5 & 0.535 & SZ17 & 0.853 & MTR36 & 0.825 \\
SE6 & 0.619 & SZ18 & 0.802 & MTR37 & 0.837 \\
SE11 & 0.598 & SZ19 & 0.912 & MTR38 & 0.887 \\
& & SZ20 & 0.867 & MTR39 & 0.856 \\
& & SZ21 & 0.895 & MTR40 & 0.774 \\
& & SZ22 & 0.606 & MTR41 & 0.439 \\
\hline CR & 0.810 & CR & 0.936 & CR & 0.911 \\
VE & 0.471 & VE & 0.649 & VE & 0.569 \\
CA & 0.807 & CA & 0.935 & CA & 0.907 \\
\hline
\end{tabular}

Note. FL - Factor Loading; CR - Composite Reliability; VE -Variance Extracted; CA - Cronbach's Alpha.

Source: Author's own elaboration.

The data indicates that the constructs offer good reliability. Only VE for SE was slightly below the 0.5 recommended by Hair, Black, Babin, and Anderson (2010), but this did not have an impact on the discriminant validity, as can be observed in Table 2.

The analysis of discriminant validity tests whether the constructs measure different aspects of DCs. Fornell and Larcker (1981) recommend that each construct's VE should be greater than the variance shared by constructs (the correlation squared). Table 2 lists comparisons between the VE for each construct (central diagonal) and the shared variances.

Table 2

Discriminant Validity of DCs Dimensions

\begin{tabular}{lccc}
\hline & SE & SZ & MTR \\
\hline SE & $\mathbf{0 . 4 7 1}$ & & \\
SZ & 0.350 & $\mathbf{0 . 6 4 9}$ & \\
MTR & 0.334 & 0.268 & $\mathbf{0 . 5 6 9}$ \\
\hline
\end{tabular}

Source: Author's own elaboration.

As can be observed, in all cases, that VE is greater than a shared variance, demonstrating the constructs' discriminant validity.

Finally, the different dimensions were all assessed in the same model to verify their fit using SEM. We chose verisimilitude as the method of estimation and the data entry matrix was the covariance matrix. Figure 2 illustrates the model estimated and the loadings for each dimension. 


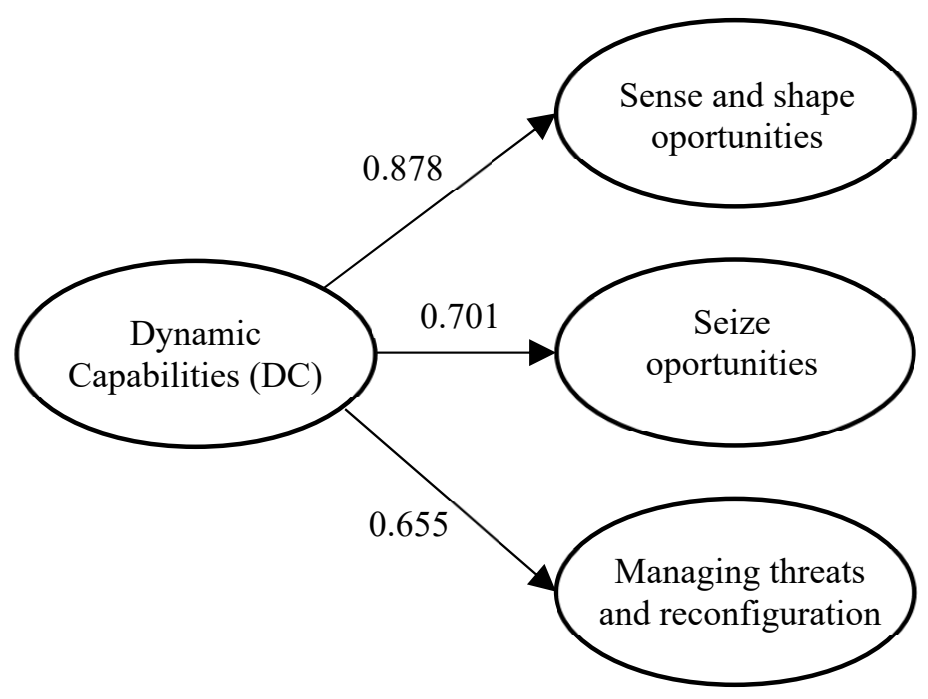

Figure 2. Model of DCs.

Source: Author's own elaboration.

Table 3 lists indicators of the model's fit.

Table 3

Indices of Fit (CFA)

\begin{tabular}{lcccccc}
\hline X2/DF & $\mathrm{p}$ & GFI & NFI & TLI & CFI & RMSEA \\
\hline 1.57 & 0.00 & 0.799 & 0.832 & 0.917 & 0.930 & 0.077 \\
\hline
\end{tabular}

Note. GFI - Goodness of Fit Index; NFI - Normed Fit Index; TLI - Tucker-Lewis Index; CFI - Comparative Fit Index; RMSEA - Root Mean Square Error of Approximation.

Source: Author's own elaboration.

The statistical results confirm the model's fit and reliability and the importance of each dimension to the formation of DCs. The same statistical procedures were applied to the constructs relating to the dependent variable. Table 4 lists the results for indicators of the reliability of performance constructs and Table 5 lists the results of the discriminant validity analysis for the constructs.

Table 4

Reliability of Performance Constructs

\begin{tabular}{lccccc}
\hline Financial Performance & & \multicolumn{2}{c}{ Strategic Performance } & \multicolumn{2}{c}{ Satisfaction with Performance } \\
\hline Ind & FL & Ind & FL & Ind & FL \\
FP43 & 0.910 & SP46 & 0.830 & SaP80 & 0.979 \\
FP44 & 0.874 & SP47 & 0.919 & SaP81 & 0.948 \\
FP45 & 0.866 & SP48 & 0.847 & SaP82 & 0.828 \\
& & & & & \\
CR & 0.914 & CR & 0.899 & CR & 0.943 \\
VE & 0.780 & VE & 0.750 & VE & 0.847 \\
CA & 0.913 & CA & 0.895 & CA & 0.939 \\
\hline
\end{tabular}

Note. FL - Factor Loading; Ind - Indicators; CR - Composite Reliability; VE - Variance Extracted; CA - Cronbach's Alpha

Source: Author's own elaboration. 
Table 5

Discriminant Validity of Performance Constructs

\begin{tabular}{lccc}
\hline & FP & SP & SaP \\
\hline FP & $\mathbf{0 . 7 8 1}$ & & \\
SP & 0.353 & $\mathbf{0 . 7 5 0}$ & \\
SaP & 0.573 & 0.415 & $\mathbf{0 . 8 4 8}$ \\
\hline
\end{tabular}

Note. FP - Financial Performance; SP - Strategic Performance; SaP - Satisfaction with Performance Source: Author's own elaboration.

All of the results observed confirmed the adequate degree of reliability.

Table 6 lists the complete questionnaire applied.

Since the results demonstrated that the constructs had adequate reliability, we proceeded to test the research hypotheses using linear regression. For this analysis, observable variables were created to represent each construct, established by their means. The following variables were created: SE (Sense), SZ (Seize), MTR (Managing threats and reconfiguration), FP (financial performance), $\mathrm{SP}$ (strategic performance) and SaP (satisfaction with performance). The variable IN (innovation) was already an observable variable. Additionally, a variable DCs (Dynamic Capabilities) was created by calculating the mean of all of the dimension variables SE, SZ, and MTR.

We constructed two regression blocks for the tests of hypotheses. The first block contains models I to IV and includes the relationships between the variable DCs and the dimensions of performance. The second block is made up of model V to model VIII, which test the relationships between the three different dimensions of DCs (SE, SZ, and MTR) and the dimensions of performance. We included Employees (EM), Revenue (RV) to control the influence of firm size and age (AG) to control the influence of experience in all models.

Table 7 lists the results of models I through IV and Table 8 lists the results of model V through model VIII.

Fulfillment of the assumptions inherent to the method was checked after the regressions have been performed. Correlations between dependent and independent variables were tested using bivariate correlations with Pearson's correlation coefficients, the results showed significant correlations between 0.518 and 0.592 . Homoscedasticity of residuals was verified using the BreuschPagan and White tests. Independence of residuals was verified using the Durbin Watson test.

Additionally, since we collected data from a single respondent at each firm (meaning the data on independent and dependent variables came from the same source), we used Harman's one-factor test to assess the common-method variance (Podsakoff, MacKenzie, Lee, \& Podsakoff, 2003). The one-factor test revealed a covariance among the variables of less than $50 \%$ indicating that there are no serious problems with common-method variance. We also verified the correlation between the subjective performances with objective performance data for a subsample of 45 companies, according to Table 9. There is a positive correlation between subjective and objective performance allowing the inference that the perception of respondents has a relationship to the results. 
Table 6

The Research Scale

Please indicate the degree to which you agree with each of the statements below using the following scale:

\section{Completely Disagree $=1 \quad$ Agree Completely $=5$}

\section{SENSE}

Our firm is constantly investing in research and development activities to identify new technologies and market opportunities.

Our firm is constantly seeking and exploring new technologies and markets both in the business we are currently in and in other businesses or sectors.

SE03 Our firm monitors the structural evolution of our business/sector.

Our firm monitors and understands the current and latent (future) demands of the market, suppliers, and competitors.

Our firm's owners and management know how to interpret the business environment, what technology they should chase and on which markets they should focus.

Our firm is constantly seeking information from different sources, such as news,

SE06 relationships, formal and informal contacts with customers, competitors and suppliers, fairs, universities, etc.

SE07 Our firm explores and monitors the development of new technologies internally.

Our firm is constantly investing and makes proactive efforts to ensure that the information collected flows between those people who are able to use it to identify new technological and market opportunities.

Our firm adopts planned and organized formal processes for collection, analysis, and use of information on new technologies and markets.

SE10 Our firm values the constant search for innovations originating outside of the firm. ns

SE11 Our firm clearly allocates resources for activities such as searching and analyzing information and discovering new opportunities in technologies and markets.

\section{SEIZE}

SZ12

Our firm is constantly developing new products, services or processes to take advantage of new technological and market opportunities.

SZ13 Our firm tends to deal very well with market change and uncertainty.

Our firm takes very good advantage of the opportunities we identify and that we judge to

SZ14 be good for our business.

Our firm has a great capacity to create, adjust and, when necessary, redesign our business plan.

SZ16 Our business plan makes it clear what our value proposal is and how it is articulated.

Our business plan estimates costs and potential revenues to meet customers' needs.

Our business plan identifies which technologies are appropriate to our business and how

Our business plan defines the structure of our value chain and where we are positioned

SZ20 Our business plan identifies and segments our target markets. 
BBR

17

58

Table 6

Cont.

Please indicate the degree to which you agree with each of the statements below using the following scale:

Completely Disagree $=1 \quad$ Agree Completely $=5$

SZ26 Our firm adopts mechanisms to prevent errors and biases in relation to the information analyzed and the decisions are taken.

We seek external analyses or opinions on our information and decisions in order to avoid errors and biases.

SZ27

We effectively use the information we have as a basis for our decisions.

We tend to request the opinions of people external to our firm as part of analyzing our decisions.

SZ30 The rewards and remuneration system at our firm encourages innovation and creativity. ns

\section{MTR}

MTR31

We know how to configure and reconfigure our resources and our organizational structure to adjust to changes and to the growth of our business.

MTR32 Our firm is flexible.

MTR33 Our firm has some type of board or forum for integration.

At our firm, we are able to identify externally in other firms or organizations assets that are complementary (specialized or cospecialized) to our requirements.

MTR35

In our firm, we have the ability to integrate and develop the assets identified externally that are complementary (specialized or cospecialized).

MTR36 We constantly identify opportunities for partnerships with external organizations.

MTR37 We find it easy to implement and manage partnerships with external organizations.

MTR38 We find it easy to integrate into our business the benefits gained from external partnerships.

The benefits we gain through partnerships with other firms constantly generate value for

MTR39 The benefits our customers.

MTR40 Our firm has a strong ability to integrate knowledge and know-how with external partners.

0.774

MTR41

Our firm manages and monitors ways of protecting our secrets and our intellectual property.

MTR42

We adopt procedures to avoid transferring technology and intellectual property to our partners.

\section{Performance}

FP43 Has been very profitable in the last 3 years.

0.910

FP44 Has generated a high volume of sales in the last 3 years. $\quad 0.874$

$\begin{array}{ll}\text { FP45 Has achieved rapid growth in the last } 3 \text { years. } & 0.866\end{array}$

SP46 Has improved its competitiveness in the last 3 years. $\quad 0.830$

$\begin{array}{lll}\text { SP47 Has strengthened its strategic positioning in the last } 3 \text { years. } & 0.919\end{array}$

SP48 Has significantly increased its market share in the last 3 years. $\quad 0.847$

SaP49 Our performance in the domestic market has been very satisfactory over the last 3 years. $\quad 0.882$

$\begin{array}{lll}\mathrm{SaP} 50 & \text { Our business in the domestic market has been very satisfactory over the last } 3 \text { years. } & 0.715\end{array}$

SaP51 Our business in the domestic market has fully met our expectations over the last 3 years. $\quad 0.879$

\section{IN}

Our products and services are more innovative than the products and services of our competitors on the domestic market.

Source: Author's own elaboration. 
Table 7

Regression Models for DCs and Performance

\begin{tabular}{lcccc}
\hline Model & I & II & III & IV \\
\hline IV & FP & SP & SaP & IN \\
DV & \multicolumn{2}{c}{ DCs } \\
CV & \multicolumn{2}{c}{ AG, RV, EM } & 5.081 \\
F & 3.120 & 3.604 & 4.431 & 0.001 \\
significance & 0.021 & 0.011 & 0.003 & 0.203 \\
adjusted r & 0.117 & 0.140 & 0.177 & $0.425^{* *}$ \\
Beta DCs & 0.121 & $0.331^{* *}$ & $0.280^{* *}$ & 0.157 \\
Beta AG & $-0.225^{*}$ & -0.142 & -0.192 & -0.099 \\
Beta RV & $0.300^{* *}$ & 0.092 & 0.217 & $0.213^{*}$ \\
Beta EM & 0.131 & 0.154 & 0.161 & \\
\hline
\end{tabular}

Note. ${ }^{* *}$ significant at $0.05 *$ significant at 0.10

Source: Author's own elaboration.

Table 8

Regression Models for Dimensions of DCs and of Performance

\begin{tabular}{lcccc}
\hline Model & V & VI & VII & VIII \\
IV & FP & SP & IN \\
DV & \multicolumn{2}{c}{ SE, SZ, MTR } \\
CV & \multicolumn{2}{c}{ AG, RV, EM } & 3.398 \\
F & 3.503 & 3.807 & 4.220 & 0.006 \\
significance & 0.005 & 0.003 & 0.001 & 0.184 \\
adjusted r & 0.190 & 0.208 & 0.232 & 0.108 \\
Beta SE & $-0.293^{*}$ & $-0.244^{*}$ & $-0.272^{*}$ & 0.121 \\
Beta SZ & $0.377^{* *}$ & $0.465^{* *}$ & $0.380^{* *}$ & $0.278^{*}$ \\
Beta MTR & -0.011 & 0.100 & 0.150 & 0.167 \\
Beta AG & $-0.257^{* *}$ & -0.172 & $-0.215^{*}$ & -0.100 \\
Beta RV & $0.389^{* *}$ & 0.180 & $0.309^{* *}$ & $0.220^{*}$ \\
Beta EM & 0.129 & 0.154 & 0.166 & \\
\hline
\end{tabular}

Note. ${ }^{* *}$ significant at $0.05 *$ significant at 0.10

Source: Author's own elaboration.

Table 9

Correlation between Subjective and Objective Performance

\begin{tabular}{lccc}
\hline & $\Delta \mathrm{S}$ & $\Delta \mathrm{C}$ & $\mathrm{ROS}$ \\
\hline $\mathrm{FP}$ & $0,366^{* *}$ & $0,455^{* *}$ & $0,329^{* *}$ \\
$\mathrm{SP}$ & $0,328^{* *}$ & $0,419^{* *}$ & $0,392^{* *}$ \\
$\mathrm{SaP}$ & $0,403^{* *}$ & $0,413^{* *}$ & $0,283^{* *}$ \\
\hline
\end{tabular}

Note. ${ }^{* *}$ significant at $0.05 ; \Delta \mathrm{S}$ sales growth; $\Delta \mathrm{C}$ growth in the number of clients; ROS return on sales Source: Author's own elaboration. 
17

60

\subsection{Discussion}

\subsubsection{DCs and Performance}

On the one hand, the results listed in Table 7 confirmed what some previous research in the area has indicated (Drnevich \& Kriauciunas, 2011; Wang \& Ahmed, 2007; Zott, 2003). There is a direct and significant relationship between DCs with organizational performance. The findings show the relationship between DCs with SP, SaP, and IN. These results supported Hypothesis 1. But, on the other hand, we did not find support to the relationship with Financial Performance, confirming other study findings - there is no relationship between DC and financial performance (Pezeshkan et al., 2016).

In fact, the results hold the controversy found in previous studies. Nevertheless, since the literature has shown that possession and orchestration of DCs have an influence on a firm's capabilities, routines, and resources, and that such relationship affects the position in the market and, consequently, its performance (Wang \& Ahmed, 2007; Zott, 2003). Possibly it is more the result of a methodological problem than a theoretical controversy. As discussed in the theoretical background, many of the researches used proxies or did a one-dimensional evaluation of DCs.

We agree DCs is a multidimensional concept (Barreto, 2010; Teece, 2007) and its different dimensions can have different influences on performance. In Table 2 we can see the discriminant validity between the dimensions of DCs, but we also can see a positive correlation between them. It means they are measuring different aspects of DCs, but these aspects have a positive correlation between them.

From this point, we have checked the influence of each DC's dimension on performance. A general overview of the results in Table 8 shows that the dimensions SE, SZ, and MTR have different results from each other and they also exhibit distinct influence on performance, depending on the different methods used to measure performance.

\subsubsection{Sense}

Hypothesis 2 proposed the existence of a direct and significant relationship between SE and performance, but, in contrast with what was expected, the relationship was negative for some measures of performance (FP, SP, and SaP). The very nature of the dimension SE implies expending efforts on research, information mapping, and market monitoring, which require allocations of resources that do not show returns in an immediate analysis; on the contrary, these are activities that demand investments. This could explain the negative relationship with performance.

In fact, the dimension Sense could be considered as a prerequisite or an antecedent of the other dimensions, not the least because of the importance demonstrated by the strength of its relationship with the other dimensions (SZ and MTR) and with the DCs construct. In this sense, the results may help to explain some results that did not find a positive relationship between DCs with performance. If any of these studies used indicators associated with the sense dimensions, the results can present somehow a bias. The results, however, also have demonstrated a positive relationship between sense, with the innovation of products and processes, even if this relationship has no statistical significance.

\subsubsection{Seize}

Seize represents the effectiveness of taking advantage of opportunities that have been identified. It signifies the transformation of ideas into new products, services, and processes which, through the 
application of strategies and well-constructed business plans, will have an impact on organizational performance.

The strategy for achieving competitive advantages is based on the adoption of technologies and appropriate business models that enable the combination and orchestration of difficult-toimitate assets (Teece, 2007). This is confirmed by the positive relationships between SZ and FP, SP, and SaP. These results support Hypothesis 3.

\subsubsection{MTR}

The MTR only had a direct and significant relationship with IN. The nature of the indicators that comprise this dimension is related to the management of partnerships with a focus on developing resources and capabilities and on the protection of assets. These indicators, by their very nature, are more related to innovation performance.

In common with SE, MTR exhibited a different relationship from that proposed at the start of the study, but it nevertheless plays an important role both in relation to the other dimensions (SE, SZ) and with relation to the DCs construct. Its role in relation to the other dimensions may be played out in an indirect manner, possibly via other capabilities, or possibly, only acting as an element of protection for capabilities or innovations.

Teece (2007) points out that reconfiguration is one way for a firm to escape from the unfavorable aspects of path dependence. It is, therefore, valid to suggest that, taking the absence of a direct relationship between MTR, and the dimensions of performance together with the results showing a negative relationship between experience and performance, the firms surveyed may be locked into the negative aspects of their paths, preventing them from acting in partnership or protecting their assets. This may be an element that is related to the industry investigated, rather than the nature of the capabilities. In view of the above, Hypothesis 4 is partially supported by the study results.

\subsubsection{Size and Experience}

Another important aspect of the results is related to the control variables. Firm size had a positive influence on several dimensions of performance, both when assessed in terms of revenue and when assessed in terms of a number of employees. This is probably because larger firms have greater access to resources and greater capacity, including financial capacity, to make investments (Musteen et al., 2010).

Experience had a negative relationship with many dimensions of performance. This may be because firms that have been established for longer are already mature in some markets and so have greater path dependence - possibly in terms of product and services lines, in terms of customers or in terms of the strategic options adopted. For this reason, change is more expensive and riskier and they find it more difficult to innovate; very often such firms have structures that have solidified and become set. As mentioned earlier, this could be a factor related to the nature of the industry studied and, for this reason, it merits investigation in greater depth in future research.

\section{CONCLUSIONS}

The most important contribution of this study has been the proposed scale for measurement of DCs. We argue that this scale is a positive evolution in relation to previous studies of the subject, the majority of which have used proxies to measure DCs. Many of these approximations adopt measures that may indeed cover certain elements of DCs, but they remain partial. Some have 
BBR

17

62

used data on new products and markets, innovation and technology, investments in R\&D, and/ or management of relationships, among others. The issue of measurement of DCs constitutes one of the most important gaps in the area and is the target of a large proportion of the criticism that has been directed at the approach. The scale allows us to reflect the integrality of the concept and presents an objective form of measurement for the DCs, as requested by Pavlou and Sawy (2011) and Eriksson (2014).

The scale proposed in this study has different characteristics. It is based on the most important concepts of DCs, it employs the three different dimensions that comprise DCs and results, both statistical and for content validity, indicate that the proposal offers good fit and reliability. A scale of this nature should contribute to expanding knowledge in the area, both by making it possible to conduct studies that can be compared with each other, because they adopt similar methodological procedures, and because it enables more robust analysis of the elements that comprise the concept. Thus, this proposal can increase the congruence in the interpretations of the role of DCs and improve the problems of divergences in DCs searches highlighted by Di Stefano et al. (2010).

Additionally, the results of the survey also make a series of contributions to the subject area and could influence the agenda for future research. In terms of academic contributions, in addition to proposing and testing the scale, this study also adds to knowledge about the roles played by the different capabilities or dimensions that comprise DCs.

The role played by the dimension Sense indicates that this is a stage or phase of investment that has a negative impact on performance, possibly because it implies effort and expenditure with no perceptible return. However, its relationships with the other dimensions and, with the DCs construct, provide evidence of its importance for performance over the long term. These results corroborate the idea that DCs allow a company to address environmental changes, adjust and reconfigure its resources to increase revenues and reduce costs (Kay, Leih, \& Teece, 2018; Teece, 2014).

The dimension Seize characterizes the importance of business plans and strategies that enable firms to take advantage of the opportunities identified. It indicates the importance of strategic capability for achieving results. It is also the dimension with the strongest direct relationship with the performance measures.

The MTR dimension only had a direct significant relationship with innovation and so invites further study aimed at improving understanding. It is possible that its role is to protect a firm's assets and contribute to its performance via innovation and relationship management. This result may also be influenced by features of the industry studied -firms in this industry may be locked into unfavorable aspects of their paths. These are obviously avenues for future research. It should, however, be stressed that the tests of fit applied to the scale demonstrate that all three dimensions are important for the measurement of DCs, showing that, working from this central contribution, the role of the dimensions should be studied in greater depth in future research.

For the executive setting, these results demonstrate with greater clarity the elements that comprise organizations' DCs and their impacts on the different dimensions of performance. This offers scope for firms to deliberately improve management of these dimensions. As is true of all scientific research, this study has certain limitations. The research was conducted in just one industry and so there is no way to control for the effects of industry on the results; the IT sector is services-intensive and services have very different characteristics from the traditional manufacturing industry; the sample of 98 respondents is too small to conduct more robust tests 
(such as structural equations modeling) to test the relationship with performance variables in a single model, which is the reason why SEM was only used in a partial manner in the study.

These contributions open up avenues for future research, for example, to verify the influences of the industry in the proposed relationships; the differences between services and manufacturing industries in terms of the relationships between DCs and their dimensions and organizational performance, and; the influences of organization's "path dependence" in the development of DCs.

\section{REFERENCES}

Ambrosini, V., \& Bowman, C. (2009). What are dynamic capabilities and are they a useful construct in strategic management? International Journal of Management Reviews, 11(1), 2949. doi:10.1111/j.1468-2370.2008.00251.x

Barreto, I. (2010). Dynamic capabilities: A review of past research and an agenda for the future. Journal of Management, 36(1), 256-280. doi:10.1177/0149206309350776

Castro, I., \& Roldán, J. L. (2015). Alliance portfolio management: dimensions and performance. European Management Review, 12(2), 63-81. doi:10.1111/emre.12042

Danneels, E. (2012). Second-order competences and Schumpeterian rents. Strategic Entrepreneurship Journal, 6(1), 42-58. doi:10.1002/sej.1127

Di Stefano, G., Peteraf, M., \& Verona, G. (2010). Dynamic capabilities deconstructed: A bibliographic investigation into the origins, development, and future directions of the research domain. Industrial and Corporate Change, 19(4), 1187-1204. doi:10.1093/icc/dtq027

Drnevich, P. L., \& Kriauciunas, A. P. (2011). Clarifying the conditions and limits of the contributions of ordinary and dynamic capabilities to relative firm performance. Strategic Management Journal, 32(3), 254-279. doi:10.1002/smj.882

Efrat, K., Hughes, P., Nemkova, E., Souchon, A. L., \& Sy-Changco, J. (2018). Leveraging of Dynamic export capabilities for competitive advantage and performance consequences: Evidence from China. Journal of Business Research, 84, 114-124.

Eisenhardt, K., \& Martin, J. (2000). Dynamic capabilities: what are they? Strategic Management Journal, 21(10-11), 1105-1121. doi:10.1002/1097-0266(200010/11)21:10/11<1105::AIDSMJ133>3.0.CO;2-E

Eriksson, T. (2014). Processes, antecedents and outcomes of dynamic capabilities. Scandinavian Journal of Management, 30(1), 65-82. doi:10.1016/j.scaman.2013.05.001

Fornell, C., \& Larcker, D. F. (1981). Structural equation models with unobservable variables and measurement error: Algebra and statistics. Journal of Marketing Research, 18(3), 382-388. doi: $10.1177 / 002224378101800313$

Hair, J. F., Black, W. C., Babin, B. J., Anderson, R. E., \& Tatham, R. L. (2010). Multivariate data analysis (7th ed.). Harlow: Pearson.

Helfat, C. E., Finkelstein, S., Mitchell, W., Peteraf, M., Singh, H., Teece, D., \& Winter, S. G. (2007). Dynamic capabilities: Understanding strategic change in organizations. United Kingdom: Blackwell Publishing.

Helfat, C. E., \& Peteraf, M. A. (2009). Understanding dynamic capabilities: Progress along a developmental path. Strategic Organization, 7(1), 91-102. doi:10.1177/1476127008100133

Kay, N. M., Leih, S., \& Teece, D. J. (2018). The role of emergence in dynamic capabilities: A restatement of the framework and some possibilities for future research. Industrial and Corporate Change, 27(4), 623-638. doi:10.1093/icc/dty015 
BBR

17

64

Kline, R. B. (1998). Software review: Software programs for structural equation modeling: Amos, EQS, and LISREL. Journal of Psychoeducational Assessment, 16(4), 343-364. doi: $10.1177 / 073428299801600407$

Laaksonen, O., \& Peltoniemi, M. (2018). The essence of dynamic capabilities and their measurement. International Journal of Management Reviews, 20(2), 184-205. doi:10.1111/ ijmr. 12122

Lin, Y., \& Wu, L. Y. (2014). Exploring the role of dynamic capabilities in firm performance under the resource-based view framework. Journal of Business Research, 67(3), 407-413. doi:10.1016/j.jbusres.2012.12.019

Musteen, M., Francis, J., \& Datta, D. K. (2010). The influence of international networks on internationalization speed and performance: A study of Czech SMEs. Journal of World Business, 45(3), 197-205. doi:10.1016/j.jwb.2009.12.003

Pavlou, P. A., \& El Sawy, O. A. (2011). Understanding the elusive black box of dynamic capabilities. Decision Sciences, 42(1), 239-273. doi:10.1111/j.1540-5915.2010.00287.x

Pedron, C. D., Picoto, W. N., Colaco, M., \& Araújo, C. C. (2018). CRM System: The role of dynamic capabilities in creating innovation capability. BBR. Brazilian Business Review, 15(5), 494-511. doi:10.15728/bbr.2018.15.5.6

Pezeshkan, A., Fainshmidt, S., Nair, A., Lance Frazier, M., \& Markowski, E. (2016). An empirical assessment of the dynamic capabilities-performance relationship. Journal of Business Research, 69(8), 2950-2956. doi:10.1016/j.jbusres.2015.10.152

Podsakoff, P. M., MacKenzie, S. B., Lee, J.-Y., \& Podsakoff, N. P. (2003). Common method biases in behavioral research: A critical review of the literature and recommended remedies. The Journal of Applied Psychology, 88(5), 879-903. doi:10.1037/0021-9010.88.5.879

Schilke, O. (2014). On the contingent value of dynamic capabilities for competitive advantage: The nonlinear moderating effect of environmental dynamism. Strategic Management Journal, 35(2), 179-203. doi:10.1002/smj.2099

Shamsie, J., Martin, X., \& Miller, D. (2009). In with the old, in with the new: Capabilities, strategies, and performance among the Hollywood studios. Strategic Management Journal, 30(13), 1440-1452. doi:10.1002/smj.789

Takahashi, A. R. W., Bulgacov, S., Semprebon, E., \& Giacomini, M. M. (2017). Dynamic capabilities, marketing capability and organizational performance. BBR Brazilian Business Review, 14(5), 466-478. doi:10.15728/bbr.2017.14.5.1

Teece, D. J. (2007). Explicating dynamic capabilities: The nature and microfoundations of (sustainable) enterprise performance. Strategic Management Journal, 28(13), 1319-1350. doi:10.1002/smj.640

Teece, D. J. (2014). A dynamic capabilities-based entrepreneurial theory of the multinational enterprise. Journal of International Business Studies, 45(1), 8-37. doi:10.1057/jibs.2013.54

Teece, D. J. (2019). A capability theory of the firm: An economics and (strategic) management perspective. New Zealand Economic Papers, 53(1), 1-43. doi:10.1080/00779954.2017.1371208

Teece, D. J., Pisano, G., \& Shuen, A. (1997). Dynamic capabilities and strategic management. Strategic Management Journal, 18(7), 509-533. doi:10.1002/(SICI)1097-0266(199708)18:7<509::AIDSMJ882>3.0.CO;2-Z 
Vogel, R., \& Güttel, W. H. (2013). The dynamic capability view in strategic management: A bibliometric review. International Journal of Management Reviews, 15(4), 426-446. doi:10.1111/ ijmr. 12000

Wang, C. L., \& Ahmed, P. K. (2007). Dynamic capabilities: A review and research agenda. International Joumal of Management Reviews, 9(1), 31-51. doi:10.1111/j.1468-2370.2007.00201.x

Wilden, R., \& Gudergan, S. (2017). Service-dominant orientation, dynamic capabilities and firm performance. Journal of Service Theory and Practice, 27(4), 808-832. doi:10.1108/JSTP04-2016-0077

Wilden, R., Gudergan, S. P., Nielsen, B. B., \& Lings, I. (2013). Dynamic capabilities and performance: Strategy, structure and environment. Long Range Planning, 46(1-2), 72-96. doi:10.1016/j.lrp.2012.12.001

Zahra, S. A., \& George, G. (2002). Absorptive capacity: A review, and extension. Academy of Management Review, 27(2), 185-203. doi:10.5465/amr.2002.6587995

Zollo, M., \& Winter, S. G. (2002). Deliberate learning and the evolution of dynamic capabilities. Organization Science, 13(3), 339-351. doi:I 04 7-7039/02/1303/0339

Zott, C. (2003). Dynamic capabilities and the emergence of intraindustry differential firm performance: Insights from a simulation study. Strategic Management Journal, 24(2), 97-125. doi: $10.1002 / \mathrm{smj} .288$

Zou, S., Taylor, C. R., \& Osland, G. E. (1998). The EXPERF Scale: A cross-national generalized export performance measure. Journal of International Marketing, 6(3), 37-58. doi: $10.2307 / 25048739$

\section{FinANCIAL SuPPorT}

This study was financed in part by the Coordenação de Aperfeiçoamento de Pessoal de Nível Superior - Brasil (CAPES)

- Finance Code 001 